\title{
Covid-19: Luto, Morte e a Sustentação do Laço Social
}

\author{
Anna Carolina Lo Bianco \\ ${ }^{1}$ Universidade Federal do Rio de Janeiro, RJ, Brasil.
}

\author{
Fernanda Costa-Moura ${ }^{1}$ \\ ${ }^{1}$ Universidade Federal do Rio de Janeiro, RJ, Brasil.
}

\begin{abstract}
Resumo: Partindo de breve contextualização da precariedade dos serviços de saúde no momento em que a Covid-19 abalroa o país, o artigo situa as condições de desamparo em que se encontra o sujeito para enfrentar a pandemia. Reconhece aí as condições para que estejamos enfrentando uma situação traumática que remete aos recursos da psicanálise para encaminhar uma forma de lidar com a situação. Recorre em seguida à conceituação psicanalítica de luto e morte identificando-os como experiências coletivas, que deveriam sustentar o pacto social e dar condições para a vida em sociedade, com suas expressões singulares. Examina as atitudes para com a morte, ao longo do último século, identificando a indiferença como uma das atitudes que ataca o referido pacto. Segue estabelecendo a importância do trabalho de luto como reverência feita à morte quando ela não é desmentida pela sociedade ou quando não se encontra nesta a atitude de indiferença para com ela. Conclui retornando ao trabalho do sujeito a partir do trauma surgido do encontro com o real da morte. Trata-se agora para este sujeito de se responsabilizar pelos enfrentamentos necessários que terão ocorrido e se impuseram a ele com a pandemia.
\end{abstract}

Palavras-chave: Covid-19, Morte, Luto, Psicanálise.

\section{Covid-19: Mourning, Death and Sustaining the Social Bond}

\begin{abstract}
Starting from a brief contextualization of the precariousness of health services at the moment when Covid-19 hits the country, the article situates the conditions of helplessness in which the subject is to face the pandemic. Then it recognizes the conditions for us to be facing a traumatic situation that refers to the resources of psychoanalysis to guide a way of dealing with the situation. It then resorts to the psychoanalytic concept of mourning and death, identifying them as collective experiences, which should support the social pact and provide conditions for life in society, with their individual expressions. It examines the attitudes towards death, over the last century, identifying indifference as one of the attitudes that attacks this pact. It goes on to establish the importance of mourning as reverence for death when it is not denied by society or when there is no attitude of indifference towards it. It concludes by returning to the subject's work once he or she faces the trauma arising from the encounter with the real of death. It is now for this subject to take responsibility for the necessary confrontations that will have occurred and have been imposed on him with the pandemic.
\end{abstract}

Keywords: Covid-19, Death, Mourning, Psychoanalysis.

\section{Covid-19: Duelo, Muerte y Sostenimiento del Vínculo Social}

Resumen: A partir de una breve contextualización de la precariedad de los servicios de salud en el momento en que Covid-19 golpea el país, el artículo sitúa las condiciones de desamparo en las que se encuentra el sujeto para enfrentar la pandemia. Allí reconoce las condiciones 
para que estemos ante una situación traumática que remite a los recursos del psicoanálisis para orientar una forma de afrontar la situación. Luego recurre al concepto psicoanalítico del duelo y la muerte, identificándolos como experiencias colectivas, que deben sustentar el pacto social y brindar condiciones para la vida en sociedad, con sus singulares expresiones. Examina las actitudes hacia la muerte, durante el último siglo, identificando la indiferencia como una de las actitudes que ataca este pacto. Continúa estableciendo la importancia del duelo como reverencia por la muerte cuando no es negado por la sociedad o cuando no se encuentra en él la actitud de indiferencia hacia ella. Concluye volviendo a la obra del sujeto desde el trauma derivado del encuentro con lo real de la muerte. Ahora le toca a este sujeto responsabilizarse de los necesarios enfrentamientos que le habrán ocurrido y le habrá impuesto con la pandemia.

Palabras clave: Covid-19, Muerte, Luto, Psicoanálisis.

Não é sem consequências o fato de que, em 11 de março de 2020, quando o estado de pandemia é declarado pela ONU, o Sistema Único de Saúde brasileiro (SUS) esteja enfrentando francos ataques de ordem política e econômica (Lima et al., 2019). Efeito das medidas implementadas pela proposta de emenda constitucional (PEC) 95, que congela o teto dos gastos federais para a saúde, o desfinanciamento do SUS fará retroceder algumas de suas políticas mais relevantes (Marques, Roberto, Gonçalves, \& Bernardes, 2019). A Estratégia de Saúde de Família, a Política Nacional de Imunização, as ações de Vigilância Epidemiológica e Sanitária, de Assistência Farmacêutica, do SAMU, da política de Aids/Hepatites, e várias outras, sofrem retrocessos impondo severos limites aos serviços ofertados à população (Morais, Oliveira, \& Vieira-daSilva, 2019). Tampouco deixa de ser um fato crucial que, neste momento, as condições de infraestrutura de água e esgoto no país sejam precárias. Segundo dados do IBGE, 9,6 milhões de residências não estão ligadas à rede de água e cinco em cada 10 casas - o que equivale a 34 milhões de domicílios - não são ligadas à rede de esgoto (Rossi \& Buono, 2020).

Mencionamos a precarização de serviços fundamentais por terem eles impacto direto na saúde e nos mostrarem em que contexto somos abalroados pela Covid-19 e seu séquito de calamidades. Esta cena se instala e é contínua com o poder de fazer morrer que vigora não apenas nas políticas de saúde, mas nas políticas de segurança pública no país. Um poder thanato-político, como o nomeia Jamart (2005), que nos deixa estatísticas escandalosas nos colocando entre os países em que a morte de jovens pretos e pardos é das maiores do mundo ${ }^{1}$. Esta falta de garantia mínima compõe nossa realidade, temos aí o quadro que mostra as condições que são as que temos para enfrentar a pandemia.

Tal panorama não abriga nenhuma perspectiva de mudança num futuro previsível, o que traz motivos de sobra para as dúvidas e incertezas que invadem, a esta altura, qualquer previsão sobre as condições de sobrevivência física e psíquica ao acontecimento. Pensemos no número de mortes causadas pela impossibilidade de acesso, de grande parte da população, à atenção básica e saneamento, somados agora à escassez dos tratamentos necessários, passando pela necessidade de isolamento, a falta de contato dos doentes com os que os cercam, falta de condições para os sepultamentos além da impossibilidade de realização das cerimônias no caso da morte.

É frente a este cenário, de saída desolador e funesto, que se coloca no presente trabalho a decisão de recorrermos às reflexões conceituais da psicanálise sobre luto e morte. Nosso objetivo será desenvolver algumas diretrizes que nos auxiliem no trabalho que temos a fazer a partir de nossa posição de sujeitos. Pois, vale dizer, o fato de estarmos enfrentando a pandemia em meio à drástica retirada de recursos e indiferença dos que exercem o poder que deveria ser público não retira dos sujeitos, um a um, a responsabilidade quanto ao que é para ser feito neste momento. Por sua vez, nosso ato de sujeito é fundamental para compor e sustentar o tecido social. Pequenos e singulares ou grandes e coletivos, em nível das instituições públicas ou privadas, vivemos dramas cujas consequências para o enfrentamento podem ser da ordem do trauma, tanto agora quanto, principalmente, depois, no que terão sido os efeitos e as marcas que a pandemia deixará.

${ }^{1}$ Ver sobre este ponto IPEA (2019). Voltaremos a ele em nota adiante. 
Evocamos essa dimensão do trauma, portanto, porque ela nos ajudará mais adiante a situar o que é próprio do trabalho singular de cada sujeito. Ou seja, o trabalho propriamente analítico que virá a ser mais fundamental do que a comoção geral - que é inevitável e perfeitamente legítima, mas não nos leva, necessariamente, a lidar melhor com o que está posto, e menos ainda concerne ao que está implicado de nossas questões subjetivas, que, como veremos, são também sociais, no modo como passamos pela pandemia.

\section{A morte como contingência}

Comecemos por considerar um dado fundamental sobre a morte. Ela só existe para os que falam. Ela é trazida pela linguagem. $\mathrm{O}$ animal propriamente não morre. Ele perece. Entre perecer e morrer há uma enorme distância que será preenchida pela vida, pelo sentido da vida, que assim passa a ser dado pela morte. Morremos, portanto, na linguagem e no sentido. E a morte dará para o falante um novo significado à vida. Tendo sido tirada de um lugar "natural" desde o pensamento grego clássico, a morte nos traz a dimensão de que somos seres mergulhados na simbolização que constituirá e afetará toda nossa forma de vida. A morte é portanto um fato de linguagem que remete e atesta nosso pertencimento a esta dimensão social em que nos movemos.

Não por acaso, as religiões e as filosofias fornecem desde sempre os meios para que a morte adquira o sentido que os falantes lhe conferem, um sentido que é social, um sentido de instituição diferente em cada sociedade, mas de qualquer forma um sentido que funciona em alguma medida "para afastar o medo (toda cultura é, entre outras coisas, uma tentativa de domar a morte)" (Redeker, 2017, p.78).

Os rituais que cercam a morte nos indicam o lugar que ela ocupa para nós quando se trata de manter o pacto social que nos sustenta na vida civilizada. Verificaremos mais adiante, porém, como a fragilização progressiva dos signos que marcam o entorno da morte, ou a impossibilidade de realizarmos e acedermos às cerimônias que a acompanham - como no caso presente de pandemia mas não apenas durante ele -, trazem uma desimbolização, uma eclipse da morte (Redeker, 2017), com efeitos sensíveis sobre as experiências subjetivas em uma sociedade.

Freud (1915/1996a) anuncia que há um zelo fervoroso que faz com que a morte seja rebaixada de necessidade para o rol das contingências que nos atingem na vida. Apesar da certeza de sermos mortais, de estarmos sob o jugo do perecível do corpo e do organismo, da inexorabilidade do fim da matéria, justamente pelo fato da morte ser fato de linguagem de sentido, portanto -, morremos, cada um a seu modo (Freud, 1921/1995). A morte passa a ser um acontecimento, a cada vez.

Dá-se então uma "atitude cultural-convencional" para com a morte que tem um forte efeito sobre nossa vida (Freud, 1915/1996a, p. 291). Sem dúvida este efeito diz respeito, acima de tudo, ao medo da morte, o qual quase sempre nos retira de quantos enfrentamentos nos são exigidos durante a vida. Nos paralisamos quando vemos que para a mãe um filho não será substituído, que para um filho o pai fará falta para sempre, que para os amantes a morte do parceiro é irrecuperável. Somos então levados a evitar que a morte seja computada no cálculo da vida, o que terá como consequências outras renúncias e exclusões, que acabam muitas vezes por fazer da vida uma sequência de evitações, denegações e acomodações.

Acontece que, tirando da vida os riscos que corremos, deixamos também de estar nela como sujeitos ao desejo, e é o desejo que traz as condições para uma vida psíquica mais rica e mais inventiva. Passamos a vida, então, a evitar o que consideramos a contingência mais dolorosa que serviria de obstáculo para sua realização. Trata-se, no entanto, de ceder à única alternativa para a vida, que é dada ao falante: viver a morte como contingente passa a ser a condição para que a vida tenha chance de se exercer e de continuar, como no evento da perda do objeto amado. Considerar a morte como contingente, pois, é uma forma de estarmos com ela no laço social, que vigora ainda hoje, mas veremos o deslocamento que esta forma sofre com o tempo e com o advento da contemporaneidade.

\section{A morte não desmentida}

A incidência da pandemia introduz um desvio acentuado neste cenário em que se constitui a experiência coletiva da morte, com sua expressão nas singularidades, que por sua vez se refere ao ponto em que estamos na civilização em que vivemos. Como não pode deixar de ser, quando nos deparamos com mais de 160 mil mortes em um breve período de menos de seis meses, quando passamos por experiências tristes com nossos conhecidos e amigos diretos e quando vemos a vida cotidiana, o estilo de vida, os hábitos, os costumes e as relações completamente mudadas 
e ameaçadas em sua própria existência, a maneira como tratamos a morte na vida muda inteiramente. Como diz Freud (1915/1996a), em circunstâncias assim a morte não se deixa mais "desmentir: é preciso crer nela" (p. 292). Vivendo durante a Primeira Guerra Mundial, quando "morrem realmente" dezenas de milhares de homens em um só dia, e "já não indivíduo por indivíduo", o autor mostra que o acúmulo põe fim à impressão de contingência que até então permeava nossa maneira de estar com a morte. Podemos certamente aqui identificar o mesmo caso pelo qual passamos neste momento de pandemia ${ }^{2}$. O que caracteriza este momento, portanto, é que se nossa atitude para com a morte, que vigorou durante muito tempo, não nos auxilia mais, tampouco temos desenvolvido recursos para lidar com o que vemos se instalar em nossas vidas - atingidas pelas perdas que enfrentamos agora.

Sobre a busca destes novos recursos para nossas relações com a morte, a Psicanálise, no entanto, tem algo a nos ensinar que ela faz derivar do que está em nós, porém oculto e "invisível para nossa consciência" (Freud, 1915/1996a, p. 293). Com o método de investigação que lhe é próprio, a Psicanálise procura situar no sujeito as condições para a manutenção do pacto social que sustenta nossa civilização. Tal método, para mencioná-lo brevemente, parte de ideias e concepções sobre o tema em questão e com elas vai à clínica e à experiência para aperfeiçoar as suas formulações conceituais - num procedimento de ida e vinda da teoria à clínica -, as quais por sua vez orientarão sua intervenção real. Reconhece inicialmente que pelas características do inconsciente, formado por moções pulsionais, este não conhece nada negativo, nenhuma "negação" - os opostos nele coincidem (Freud, 1915/1996b, p. 297). Como no sonho, uma coisa pode ser algo e seu oposto. Logo, a morte a que só podemos dar um conteúdo negativo não é conhecida pelo inconsciente. Nesse sentido, nada pulsional em nós solicita a crença na morte, em nossa própria morte.
No entanto, não temos problema em admitir a morte de estranhos e mesmo em desejar a morte de inimigos, se bem que, importante frisar, a admitamos em pensamento apenas, ou em desejos. O fato de admitirmos a morte de outros é bastante significativo e trará algumas consequências importantes. Assim é que no inconsciente liquidamos diariamente quem nos estorva o caminho, quem impede a realização de nossas vontades e contraria as nossas intenções e decisões. E às vezes os aniquilamos por quaisquer bobagens. Por mais que custemos a crer conscientemente nisso, vemos que o desejo inconsciente é apenas congruente ao querer a morte daquilo que nos impede de nos realizarmos e nos sustentarmos como eu.

Certamente, o fato destas "secretas predisposições” não possuírem a força capaz de executar os assassinatos - por encontrarem limites intrínsecos à vida em cultura - é responsável pelo que faz sobreviver a humanidade como tal até os nossos dias. Desde épocas bem longínquas se dá a aparição da proibição de matar. E Freud (1915/1996a) observa que "uma proibição tão forte só pode ter sido erigida contra um impulso igualmente forte" (p. 297). E, acrescenta: “o imperativo do mandamento 'Não matarás' nos dá a certeza de que somos da linhagem de uma série interminável de gerações de assassinos que tinham no sangue o gosto de matar, como talvez ainda tenhamos hoje" (p. 297).

Freud recorre ao mito para falar do fato de termos sobrevivido à barbárie dos assassinatos que teriam sido irreprimíveis, mas foram contidos por um pacto ditado pela necessidade de sustentação da vida em sociedade. Considera então que reconhecermos a verdade sobre o nosso desejo de morte do que nos é estranho e outro talvez seja o recurso que possamos usar para enfrentar em nós mesmos tal desejo, e nos dedicarmos a fazer a convivência mais satisfatória para todos e para cada um. É na identificação de nossas moções agressivas que teremos as condições

\footnotetext{
${ }^{2}$ Uma outra aproximação que podemos fazer neste ponto diz respeito às mortes decorrentes de ações policiais exercidas nos morros e favelas cariocas. Apesar da precariedade de estatísticas oficiais, estudos recentes comprovam que houve efeitos drásticos de redução de violência a partir da medida cautelar ADPF 635, que determinou a suspensão de operações policiais em favelas do Rio de Janeiro durante a pandemia (Hirata, Grillo, \& Dirk, 2020). Não conhecemos nenhum estudo sistemático da psicologia do luto e da morte nesta população. Mas certamente uma criança que sai para a escola e, dia sim dia não, vê um corpo estendido no chão, tem uma relação com a morte que, por seu excesso, invade a vida e tem poucas condições de ser recalcada. As mães que se unem para chorar a perda dos filhos recém saídos da adolescência, mortos em série devido à política de morte que vigora nas comunidades, provavelmente não podem manter mais a impressão de que a morte é um acaso que as atingiu. Certamente, pode-se fazer a pergunta que interroga a má sorte de por que aquele projétil fez aquele percurso naquele instante, mas a própria questão e as respostas dadas são poucas e frágeis para falar da quantidade de casos que se repetem. A inexorabilidade da morte no cotidiano das favelas tem que ser encarada pelos favelados, sem rodeios. Não lhes deve ser possível conceber a morte como acaso.
} 
de as ultrapassarmos, ou melhor, de renunciar a elas em prol de uma vida comum. Nos vemos aqui diante de uma conquista da história e das aspirações éticas da humanidade. Resta-nos, pois, um patrimônio a sustentar, e o encontro com a pandemia, bem como o tempo posterior a ela, nos colocam a pergunta: teremos honrado o encargo que leva a esta sobrevivência?

\section{A morte negada e o real da Covid-19}

Nossa atitude atual em relação à morte, mesmo na época em que não estávamos na pandemia, não nos traz notícias muito animadoras para respondermos sobre a nossa tarefa neste ponto - esta que apontamos anteriormente, de conter os impulsos assassinos e mortais para entrarmos no pacto social e o respeitarmos, em nome de preservar a vida comum. Por cada vez menos suportarmos o encontro com a morte, e por cada vez menos darmos lugar ao que se perde na vida, são também escassos os meios que temos para fazermos face a ela e a suas repercussões e derivações. Isto nos pede um esforço a mais na hora em que estamos frente ao perigo da morte e a todas as perdas relativas à pandemia na vida de cada um, bem como na vida das instituições do país. É preciso aí um esforço a mais que nos leve a não negar a morte para termos as condições necessárias para enfrentá-la neste momento.

No entanto, como exporemos agora, e uma ampla bibliografia nos auxilia aqui, o cenário em que a morte é concebida nos dias atuais no limite a exclui ou, quando menos, procura escamoteá-la, ou apagá-la em seus efeitos mais conspícuos. Não entraremos nos motivos pelos quais a perda e os fracassos normais da vida são cada vez mais inaceitáveis e banidos de nosso horizonte ${ }^{3}$, mas certamente a morte é igualmente exilada de nosso cotidiano. O que nos importa particularmente aqui é reconhecermos que o lugar que damos ao morrer e à morte vem pouco a pouco sendo, digamos, higienizado de seus horrores e dos medos que os acompanham, mas também de sua dimensão de contingência, que até então prevalecia, quando a confrontávamos. À medida em que a morte passa a ser apagada da vida comum, podemos falar também de uma banalização da morte e do morrer sem precedentes nas sociedades anteriores, ainda que consideremos a história de todas estas sociedades como a história escrita com as suas guerras cruentas.
Diversos autores vêm apontando um progressivo ocultamento da morte nas sociedades industrializadas e urbanizadas do chamado mundo ocidental, que se dá banindo-a da experiência comum ou, quando muito, transferindo-a para os hospitais onde permanecerá mais do que nunca escondida (Tamura, 2007). Em estudo já clássico, Ariès (1974/ 2003), valendo-se de cortes temporais amplos e de uma visão geral sobre as atitudes em relação à morte ao longo dos séculos, mostra que essa acaba antes de tudo por se tornar um evento médico, cujos sentimentos que elicita devem ser banidos, por mostrarem uma instabilidade mental que seria mesmo de mal gosto expressar. Tanto aquele que morre quanto os que estão em seu entorno são afastados das condições da morte. Esta passa agora a ser predominantemente um assunto medicalizado. Morre-se submetido a tratamentos medicamentosos avançados, resultantes das pesquisas científicas de ponta, que utilizam instrumentos precisos, que por sua vez necessitam que o doente esteja internado por longos períodos. A morte não é mais acompanhada pelos que estão à volta do moribundo (Elias, 2001). Torna-se muitas vezes vergonhosa e proibida.

Em interessante artigo, ainda tratando desta dimensão de apagamento da morte, Jamart (1998) reporta uma curiosa anedota de quando, no hospital em que trabalhava, um belo dia, colocou-se um aviso no lugar de culto onde as pessoas iam fazer as orações por seus doentes de que na semana seguinte ele estaria fechado, para que a capela pudesse ser usada para alojar os stands de uma feira de demonstração das últimas novidades tecnológicas de exploração gastroenterológica. A autora vê neste pequeno incidente a expressão da impossibilidade de que qualquer coisa do humano fosse elevada ao estatuto de sagrado. Nem mesmo a morte poderia fazer contrapeso, afirma, à onipotência do aparato tecnológico que o mundo valorizou com as possibilidades inauguradas pela ciência, mas que certamente são utilizadas de acordo com interesses que a ultrapassam. Trata-se agora de um affaire de tecnologia, e Jamart (1998) vai mais longe ao falar de um "genocídio da morte" que faz do hospital um lugar potencial de barbárie.

Vivemos numa época em que a morte é ignorada, neste sentido de que não temos muito a dizer sobre ela que não seja em termos cientificistas, biológicos e médicos. Termos que acabam por excluí-la, colocá-la

\footnotetext{
${ }^{3}$ Ver acerca destes motivos, por ex., a entrevista do site "A Fita" com Achille Mbembe (A Fita, 2019).
} 
à margem, afastá-la para os subsolos dos grandes hospitais, para as morgues e necrotérios, onde ela se prova mais do que nunca um evento à parte do mundo dos vivos.

Nesta eclipse da morte, como afirma Redeker (2017), produz-se uma impossibilidade de simbolização que não nos deixa dar chance à morte, não nos permite dar a ela um lugar - contingente que seja -, tornando-a algo pouco reconhecido; pois, como vimos anteriormente, "ela é simbolizada ou ela não é, ela é simbolizada ou não é nada” (p. 44). O autor chama atenção para o desaparecimento da morte em níveis bem prosaicos, de nosso dia a dia, como usarmos outros vocábulos para nos referirmos a ela, numa verdadeira "ocultação léxica da morte" (p. 45), que passa a ser referida por um sem número de termos mais ou menos técnicos que servem para afastar e esconder o de que se trata. Não dar chance à morte é, pois, quase não supor sequer que ela venha a nos atingir na vida, é não admitir que ela nos aconteça, ou que iremos encontrá-la em algum ponto da vida, por inesperado que seja, por contingente que a consideremos no momento em que ela ocorre.

Sem dúvida que ao assassinarmos e aniquilarmos a morte começamos a entrar num mundo de larvas, num mundo perigoso que é preciso abordar com cuidado. Não querermos admitir a verdade sobre nossas moções agressivas é não admitirmos o que há de ser elaborado, trabalhado e recalcado para que a vida em sociedade se torne exequível. Não termos presente a dificuldade que é lidar com a morte, e com a violência que a circunda, é também não discernirmos e não chamarmos cada um para o esforço necessário para ultrapassar em nós as moções de agressividade que são parte de nossa constituição como sujeitos em cultura. Trata-se de uma longa história de vencermos a cada ponto o desejo que nos habita de aniquilamento do outro, para termos um convívio possível. Ao nos afastarmos dessas moções agressivas em nós mesmos, perdemos a possibilidade de nos responsabilizarmos subjetivamente por sua incidência em nós e em nossa volta, e recrudescemos esse afastamento da morte da vida a partir do qual sequer como contingência ela é admitida.

No entanto, se nos traz horror encararmos as moções agressivas, maior horror será negar a própria existência da morte, e recebê-la com indiferença. Colocando de forma que talvez nos diga mais respeito e fale mais de perto à nossa experiência nestes dias com a Covid-19, uma das formas de enfrentarmos e respeitarmos a morte tem início no reconhecimento de que a morte do outro não me pode ser indiferente, pois a indiferença é que leva ao perigo de nos perdermos num gozo mortífero, que pode se tornar a danação da vida em sociedade.

\section{Dando lugar à morte}

Ao contrário, mostramos um mínimo de cuidado quando escutamos o chamado do real da pandemia. Este real será ouvido quando relativizarmos a onipotência médica e quando não colocarmos o progresso e a riqueza como donos da vida e da morte; quando admitirmos que o conhecimento científico não domina todo o saber sobre o vírus; que a doença que nos acomete traz inúmeras incertezas; que não temos o remédio infalível e menos ainda a vacina salvadora de nossas vidas. E assim, se nos curvamos às mais de 100 mil mortes, neste ponto mesmo, mostramos a preocupação com o que temos que trabalhar, com o esforço que temos que fazer em conjunto, como nações, como sujeitos e cidadãos, usuários, mas também submetidos aos produtos da ciência, para que os efeitos e as consequências da pandemia não dilacerem de forma irrecuperável o tecido social. Perguntamo-nos mesmo se a medicina não encontraria agora condições para sua tão decantada humanização, que tantas vezes não passou de uma eficaz estratégia de marketing para uma medicalização que seria igual a uma tecnologização mais eficaz da vida.

Passamos a dar lugar agora ao trabalho de luto que vem desde sempre nos falar do lugar dado à morte na sustentação do laço social, sofrendo os efeitos e as vicissitudes das várias atitudes para com a morte. O momento da pandemia, especificamente, é quando as condições para se fazer o luto estão ameaçadas, não apenas por todo o perigo de contágio que interrompe os rituais, mas também porque desaparece o tempo e o espaço para um trabalho (e não à toa enfatizaremos este termo, trabalho, tantas vezes ao falar de luto), que é altamente individual e pessoal, de estarmos com o acontecimento que nos atinge.

Tomando-o ainda em sua dimensão de um trabalho coletivo, podemos reconhecer no luto a ser feito a tentativa de recomposição de uma malha social que se esgarça por um buraco feito na trama, de uma cadeia que se rompe com a quebra de um elo. Ainda que exatamente se trate de cada um vir a tomar um lugar que é singular, este lugar é dado pela posição 
dos outros elementos na série. É o luto experimentado a cada caso que vem nos dar ideia do que a morte de uma pessoa representa e exige de trabalho para que a teia que se rompe com sua saída da cadeia de relacionamento volte a se recompor.

Com a morte de um familiar, de um amigo ou de um companheiro, toda a malha, todo o tecido social, se afrouxa, e a pergunta não é apenas o que eu perdi ao perdê-lo ou o que ele representava para mim, mas antes que lugar eu tinha e acabo de perder na vida social, que lugar me era dado ocupar, que relevância eu tinha ou não tinha que agora eu vejo se perdendo e que haverá de se reconstituir. É, portanto, de mim, como sujeito, que se trata na morte do outro. Tem-se agora de abandonar o lugar que cada um ocupava ou que a cada um era dado, desde que um elo vem a faltar na cadeia. É preciso que um trabalho seja feito para que este abandono seja experimentado e a teia venha a se recompor. Todas estas minuciosas e delicadas manobras que envolvem o luto encontram-se repentinamente banidas no momento em que a pandemia se instala.

Os estudos etnográficos em que o clássico de Mauss (1921/1969) A expressão obrigatória dos sentimentos se baseia falam do caráter das cerimônias públicas e de sua regulamentação muito precisa. Mostram o lugar que o luto ocupa nas sociedades e como o reconhecimento da morte articula e estrutura a rede social. No estudo dos rituais orais dos cultos funerários australianos, Mauss verifica que o choro e outras expressões orais neles presentes não são exclusivamente psicológicos ou fisiológicos: são antes fenômenos sociais. E vale a pena enfatizar que o caráter coletivo das expressões dos sentimentos não prejudica em nada a intensidade destes, muito pelo contrário: os ritos põem em ação sentimentos e ideias coletivas, e têm a vantagem de nos fazer entrever o grupo, a coletividade em ação ou mesmo em interação. Mauss revela que é preciso emitir os gritos e os cantos porque todo o grupo os entende. $\mathrm{E}$ acrescenta que se trata de mais do que uma manifestação dos próprios sentimentos, pois neles temos um modo de manifestá-los aos outros, "manifesta-se a si, exprimindo aos outros, por conta dos outros" (p. 278).

Tradicionalmente os ritos e as práticas rituais são objeto de estudo da antropologia e da sociologia. No entanto, na psicanálise podemos valorizá-los sobretudo porque permitem um enodamento entre o registro do pulsional e os semblants que regem o laço social (Estenne, Jamart, \& Marchal, 2017). Vale dizer, os ritos ligam o individual ao coletivo. Organizam o pulsional e o colocam em forma com uma dimensão de inscrição no corpo. No caso do luto e da morte, $\mathrm{o}$ rito permite que se dê uma resposta à irrupção do real da morte, e, colocando um véu sobre o buraco que tal irrupção causa, "propõe uma interpretação da desordem, do sintoma individual enquanto concernido com o coletivo" (Estenne, Jamart, \& Marchal, 2017, p. 17), ou melhor, dá as condições para que se reinstitua a identidade dos sujeitos bem como seu pertencimento ao coletivo, depois do enfrentamento da morte de um objeto amado.

Aquele ou aquela que perdemos ocupava um lugar na cadeia de relacionamentos que agora encontra-se vazio. Trata-se de nos havermos neste momento, repetimos, com o fato de que toda a cadeia é afetada no momento em que um dos elos se solta. A pergunta "que lugar a pessoa que morreu ocupava na vida de cada pessoa com quem ela convivia?" remete de imediato a uma série de outras questões que por sua vez dão notícia de que se trata de toda uma rede social atingida. Portanto, é o lugar de cada um, e de um a um, que está em jogo, porque se trata não apenas de saber o que o morto representa para mim, mas que lugar me era dado na vida social pela minha relação com quem morreu.

É, portanto, sob a perspectiva de um trabalho que reinstaura o lugar perdido do sujeito que podemos entender o luto como parte de uma reverência feita à morte, particularmente quando pensamos em sua dimensão impossível de ser desmentida. Mas, como dissemos, no entanto, se podemos identificar no trabalho de luto sua dimensão social, trata-se simultaneamente de um trabalho individual que necessita um grande esforço, numa época em que justamente a perda que sofremos nos abate e entristece, nos deixa sem forças.

Os efeitos dessa perda são sempre muito visíveis, porque não abrimos mão facilmente de alguém com quem tínhamos tantas vezes intensas trocas de afetos, fossem elas prazerosas ou não. Quantas vezes escutamos alguém intrigado por estar se vendo inconsolável com a perda de uma pessoa com quem vivia brigando e de quem muitas vezes sentira tanta raiva? Principalmente se a nossa vida está organizada em torno de alguém que não está mais ali, contando com nossa presença, o que fazer com esta falta? Uma sensação de vazio se instala, de que nada mais vale a pena. 
O fato de não podermos nesse momento cumprir os variados ritos de despedida, das diversas regiões do país, a que estamos acostumados trará consequências para que se comece a fazer o trabalho de luto necessário. As formalidades do velório, do enterro ou da cremação que nos servem para aos poucos irmos nos acostumando à ideia de que não estaremos mais com quem morreu seriam cruciais para nos iniciarmos no luto a ser realizado. Mas o que fará mais falta, talvez, será o período que se segue à morte e ao enterro, o de chorarmos juntos, de nos consolarmos uns aos outros e repetirmos o quanto estamos tristes, desesperançosos e sofridos. A impossibilidade de estarmos fisicamente uns com os outros, abraçarmos aos mais próximos, que muitas vezes estarão sofrendo o mesmo que nós, é o que mais assusta e nos deixa desamparados nesta hora. É, então, de nos perguntarmos que efeitos as recomendações para distanciamento causarão àqueles que as observam.

Neste momento também todos os que lidam com a morte, enfermeiros, médicos, técnicos de enfermagem, psicólogos e fisioterapeutas que nos hospitais estão acompanhando os doentes e perdendo muitas vezes a luta de forma inquietante, estão se havendo com situações surpreendentes, impossíveis de serem evitadas ou apagadas. Ao contrário, se trata nestes instantes de reunir recursos que ajudem a reconhecer e enfrentar a presença da morte e do morrer.

Relatos pungentes sobre a dificuldade de identificação dos mortos mostram muitas vezes como os profissionais se desdobram para marcar uma morte, não deixá-la se perder no inumerável das quantidades, uma vez, por exemplo, que os caixões não podem ser abertos. As equipes de psicologia neste ponto têm uma função essencial. Lembramos especificamente do caso de uma bebê falecida com suspeita de contaminação pela Covid-19. Como dar a garantia aos pais de que aquela recém-nascida que iriam sepultar estava de fato no caixão que lhes tinha sido entregue. Como fazer valer a morte que possibilita o trabalho de luto, que por sua vez inscreve a morte da filha na vida da família. Foi um esforço grande da equipe comandada por uma psicóloga que possibilitou inscrever, com vários expedientes - como fotos, mensagens escritas e peças de roupa envolvendo o pequeno caixão -, a morte de alguém que, sim, esteve na vida. Pelo menos as condições foram dadas para que o reconhecimento da morte não tornasse aquele acontecimento algo que dissesse apenas da diferença entre o vivo e o inerte. A morte de um que seja vivo não nos pode deixar indiferente.

Da mesma forma é preciso nos indagarmos como estarão sendo tocados os que tratam dos corpos nos hospitais, nos serviços funerários, os coveiros e todo o pessoal que convive com a morte neste momento. Quando não envolvidos diretamente com uma perda em particular, estão vendo seus cotidianos, que já não eram fáceis, invadidos por uma sequência de mortes infindáveis. Por mais que até mesmo treinados em situações de desastres e emergências, a tristeza e o impacto das cenas que estão vivendo deixarão marcas difíceis de serem apagadas.

\section{Considerações finais: Sujeito ao trauma e à pandemia - o lugar do ato}

Depois de traçarmos as vicissitudes que cercam a morte na vida do humano, procuraremos, para finalizar, falar do que temos a fazer hoje, de nossa posição de sujeitos, com o que terão sido as marcas e os efeitos da Covid-19. Como afirmamos de início, o conceito psicanalítico de trauma virá em nosso auxílio para situar o que está em jogo aqui. Trata-se da tomada de uma posição ética de enfrentamento de uma situação que nos força a não esconder o horror, mas tampouco sucumbir ao pânico e menos ainda à covarde indiferença.

Voltamos a Freud (1921/1996a), quando, na virada dos anos 20 do século passado, mais uma vez se vale de experiências da vida cotidiana durante a Grande Guerra para retraçar a incidência cruel da contingência e da morte no cerne da vida do sujeito. Passa agora a observar as respostas que o sujeito dá ao que o marca - e chama atenção para a fixação e a repetição que o tomam quando vive uma situação traumática. O conceito central que orienta o psicanalista em suas elaborações e principalmente em sua clínica, neste ponto, é a pulsão. Sua característica tal como a concebe é de impelir à busca da satisfação e produzi-la inexoravelmente, ainda que ela acarrete algum sofrimento. Trata-se de um conceito que se refere a algo de paradoxal, portanto. Nele se elicita a compulsão à repetição que permeia o funcionamento pulsional do falante (Freud, 1915/1996b). Podemos sempre declinar o real que sobrevém do trauma que nos açoda e da repetição a que somos sujeitos como puro acontecimento, externo, exterior, alteritário. No entanto, um sujeito irá trabalhar para, uma vez sendo tocado por este real, chegar a localizar sua própria posição neste acontecimento; ou, ao menos, no que é feito dele para si. 
Do acontecimento real surgem os encontros com as posições que tomamos. Tais posições são fruto de uma "intencionalidade" inconsciente que não é deliberada, não se pauta pelo prazer e inclui a satisfação (pulsional). Além disso ela é prenhe de consequências no que diz respeito à realização e à elaboração de nossa condição de sujeitos ao desejo.

Vemos que para um falante o trauma insuportável pode vir a se inscrever como falta radical de sentido e de recursos. Como na situação que vivemos atualmente, esta falta de recursos deixa aberta para o sujeito uma única via que é a de tomar lugar aí e no mesmo passo se responsabilizar pelos enfrentamentos necessários que terão ocorrido e que se impuseram a ele.

Embora as religiões e mesmo a ciência encaminhem (ou pareçam encaminhar) diversos sentidos possíveis neste ponto, a contingência da coisa toda, ou, como dissemos anteriormente, o que nos abalroa, é brutal. Temos nada mais que essa 'presença', algo xenopática, que o discurso da ciência delimitou como o novo coronavírus e que passou a povoar nossas vidas. Até um certo ponto, as explicações e os protocolos da ciência nos acalmam um pouco e nos fazem entrever alguma ordem, mesmo que a presença da morte, sua contingência insensata, se encontre sempre no fundo da cena. Mas dura mesmo é a apreensão que podemos ter de que, não só isso não faz nenhum sentido - senão o de ser uma ameaça bem real, sem outro propósito que não os riscos inerentes da vida que segue adiante -, como se trata de um acaso (poderia ser outra coisa, um asteroide, uma guerra, mais uma usina atômica), e, no entanto, trata-se de um acaso de certa forma previsível e ao mesmo tempo inevitável - é assim a contingência, brota de qualquer lugar.

E mais, o que está posto para nós, o que isso coloca (o que coloca a neutralidade, a falta de intencionalidade disso que é o real), é que, se quisermos encontrar uma saída, só nos resta nos submetermos ao vírus, a isso que vem do real, à sua dinâmica. Estamos por assim dizer objetalizados por "ele". Estamos também dentro dos discursos que nos constituem, como a ciência (que o produz no ato em que o identifica, que o reporta às muitas mortes, e que tem legitimidade justamente enquanto não pretende saber o que é) e o regime de trocas induzido pelo capitalismo atual. Temos que admitir que estamos diante de um vírus impossível de dominar, para termos alguma chance de fazermos o que precisa ser feito a partir disso.

Sem dúvidas a solidariedade é necessária. Sem ela tudo seria ainda pior do que já se sabe (pela ciência) que será. Mas é nesse ponto que, assim o propomos, alguma advertência da psicanálise pode ter valor. A comoção geral é um efeito de termos que suportar o que não tem sentido algum, mas que é bem real. Por meio dela, ou com ela, nos submetemos e executamos os protocolos inevitáveis. Mas é importante que essas operações não tamponem ou escamoteiem o sem sentido da coisa, sua contingência - porque há que se encontrar com isso. Se a sustentação de nosso laço social não passa simplesmente por pretender ter os meios de promover a felicidade geral - Freud (1921/1996b) já colocava em questão essa aposta utilitarista que tentamos a todo custo promover -, resta para o falante estar o mais rente, tanto quanto possível, do real; afrontando, no limite, o fora de sentido que habita o cerne de nossas vidas frágeis.

Reconhecer e estar mais próximos de nossos próprios limites é justamente a via estreita de que dispomos para, quem sabe, encontrar aqui e ali um novo equacionamento para os nossos impasses. Assim, num mundo eventual pós-pandemia não se tratará, muito provavelmente, de apenas restituir um modo de vida anterior que, a essa altura, tende a ser situado como o melhor dos mundos. Sabemos que esta esperança, como toda esperança, não se sustenta. Tampouco podemos viver do amor da recordação, do que se foi. Trata-se então de coragem para enfrentar apenas a certeza do instante em que fazemos o que há de ser feito; só depois virá a notícia do que teremos sido durante o tempo da pandemia.

\section{Referências}

A Fita. (2019, 30 de Outubro). Outras fitas: Descolonização, necropolítica e o futuro do mundo. http://afita.com.br/ outras-fitas-descolonizacao-necropolitica-e-o-futuro-do-mundo-com-achille-mbembe/

Ariès, P. (2003). História da morte no ocidente. Ediouro. (Trabalho original publicado em 1974)

Elias, N. (2001). A solidão dos moribundos. Zahar.

Estenne, M., Jamart, C., \& Marchal, P. (2017). Nécessité et fonctions des rites aujourd'hui: Qu'en pense la psychanalyse. Le Bulletin Freudien, 62, 15-18. 
Freud, S. (1995). Psicología de las masas y análisis del yo. In A. Freud \& J. Strachey (Eds.), Sigmund Freud Obras Completas: Vol. 18. Más allá del principio de placer: Psicología de las masas y análisis del yo yotras obras (1920-1922) (pp. 63-136). Amorrortu Editores (Trabalho original publicado em 1921)

Freud, S. (1996a). Nuestra actitud hacia la muerte. In A. Freud \& J. Strachey (Eds.), Sigmund Freud Obras Completas: Vol. 14. Contribuición a la historia del psicoanalítico: Trabajos sobre metapsicologia y otras obras (1914-1916) (pp. 290-301). Amorrortu Editores. (Trabalho original publicado em 1915)

Freud, S. (1996b). Pulsiones y destinos de pulsión. In A. Freud \& J. Strachey (Eds.), Sigmund Freud Obras Completas: Vol. 14. Contribuición a la historia del movimiento psicoanalítico: Trabajos sobre metapsicologia y otras obras (1914-1916) (pp. 105-134). Amorrortu Editores. (Trabalho original publicado em 1915)

Hirata, D., Grillo, C. C., \& Dirk, R. (2020). Apresentação ao relatório Efeitos da Medida Cautelar na ADPF 635 sobre as Operações Policiais na Região Metropolitana do RJ. Dilemas. Rio de Janeiro, pp. 1-11.

Instituto de Pesquisa Econômica Aplicada. (2017, 6 de Junho). Atlas da Violência. https://www.ipea.gov.br/ atlasviolencia/

Jamart, C. (1998, 6-7 de Março). Du devoir d'écrire [Sessão de conferência]. Colloque Soins Palliatifs à Domicile, Centre de Santé Liégeois, Liège, Bélgica.

Jamart, C. (2005). Questions de mort - questions de vue. Journées d'étude de L'Association lacanienne internationale. Psychanalyse et travail social. Paris. 12 et 13 mars

Lima, H. S. C., Felipe, J. S., Silva, J. A. A., Temporão, J. G., Padilha, A. R. S., \& Reis, A. A. C. (2019). SUS, saúde e democracia: Desafios para o Brasil: Manifesto de seis ex-ministros da saúde a propósito da $16^{\text {a }}$ conferência nacional de saúde. Ciência \& Saúde Coletiva, 24(10), 3713-3716. http://dx.doi.org/10.1590/1413-812320182410.21932019

Marques, C. F., Roberto, N. L. B., Gonçalves, H. S., \& Bernardes, A. G. (2019). O que significa o desmonte? Desmonte do que e para quem? [Número especial]. Psicologia: Ciência e Profissão, 39(2), Artigo e225552. https:// doi.org/10.1590/1982-3703003225552

Mauss, M. (1969). L'expression obligatoire des sentiments. In Euvres: Vol. 3. Cohésion sociale et division de la sociologie (pp. 269-278). Les Éditions de Minuit. (Trabalho original publicado em 1921)

Morais, H. M. M., Oliveira, R. S., \&Vieira-da-Silva, L. M. (2019). A coalizão dos empresários da saúde e suas propostas para a reforma do sistema de saúde brasileiro: Retrocessos políticos e programáticos (2014-2018). Ciência \& Saúde Coletiva, 24(12), 4479-4488. https://doi.org/10.1590/1413-812320182412.25802019

Redeker, R. (2017). L'eclipse de la mort. Descleé de Brouwer.

Rossi, A., \& Buono, R. (2020, 27 de Julho). Pandemia sem água na torneira. Piauí. https://piaui.folha.uol.com.br/ pandemia-sem-agua-na-torneira/

Tamura, C. (2007, 16 de Junho). O recalcamento da morte na contemporaneidade. https://www.unicamp.br/iel/site/ alunos/publicacoes/textos/r00007.htm

\section{Anna Carolina Lo Bianco}

Professora Titular do Programa de Pós-graduação em Teoria Psicanalítica do Instituto de Psicologia da Universidade Federal do Rio de Janeiro, Rio de Janeiro - RJ. Brasil.

E-mail: aclobianco@uol.com.br

(1) https://orcid.org/0000-0001-6276-1321

\section{Fernanda Costa-Moura}

Professora Associada do Programa de Pós-graduação em Teoria Psicanalítica do Instituto de Psicologia da Universidade Federal do Rio de Janeiro, Rio de Janeiro - RJ. Brasil.

E-mail: costamouraf@gmail.com

(1) https://orcid.org/0000-0001-6138-9804

Agradecimentos:

$\mathrm{CNPq}$

Mila Lo Bianco 
Endereço para envio de correspondência:

Rua Duque Estrada, 46, apto. 901, Gávea. CEP: 22451 090. Rio de Janeiro - RJ. Brasil.

Recebido 12/08/2020

Aceito 29/09/2020

Received 08/12/2020

Approved 09/29/2020

Recibido $12 / 08 / 2020$

Aceptado 29/09/2020

Como citar: Lo Bianco, A. C., \& Costa-Moura, F. (2020). Covid-19: luto, morte e a sustentação do laço social. Psicologia: Ciência e Profissão, 40, 1-11. https://doi.org/10.1590/1982-3703003244103

How to cite: Lo Bianco, A. C., \& Costa-Moura, F. (2020). Covid-19: mourning, death and sustaining the social bond. Psicologia: Ciência e Profissão, 40, 1-11. https://doi.org/10.1590/1982-3703003244103

Cómo citar: Lo Bianco, A. C., \& Costa-Moura, F. (2020). Covid-19: duelo, muerte y sostenimiento del vínculo social. Psicologia: Ciência e Profissão, 40, 1-11. https://doi.org/10.1590/1982-3703003244103 